\title{
Ansiedade e depressão em mulheres vítimas de violência doméstica
}

\author{
Anxiety and depression in women suffering domestic violence
}

Danielle Bittar ${ }^{[a]}$, Marina Kohlsdorf ${ }^{[b]}$

\footnotetext{
[a] Graduada em Psicologia pela Universidade Católica de Brasília (UCB), Brasília, DF - Brasil, e-mail: danipsico21@hotmail.com

${ }^{[b]}$ Doutora em Processos de Desenvolvimento Humano Saúde pela Universidade de Brasília (UnB), professora da Universidade Católica de Brasília (UCB), Brasília, DF - Brasil, e-mail: marinak@ucb.br
}

Recebido: 09/12/2012 Received: $12 / 09 / 2012$

Aprovado: 21/03/2013 Approved: 03/21/2013

\begin{abstract}
Resumo
O objetivo desta pesquisa quantitativa foi avaliar o nível de depressão e ansiedade em mulheres vítimas da violência doméstica, além de caracterizar o tipo de violência sofrida. Foram avaliadas 15 mulheres com idade entre 25 e 62 anos que deram entrada em uma delegacia de polícia com queixa de violência doméstica e estavam em acompanhamento psicossocial no Núcleo de Atendimento à Família e dos Autores de Violência Doméstica (NAFAVD- Brazlândia) da Secretaria de Estado da Mulher (SEM). Foram aplicados três questionários: o primeiro visa obter dados sobre o perfil da violência e dados demográficos das participantes; o segundo é Inventário Beck de Depressão (BDI), instrumento que avalia os sintomas depressivos; e o terceiro, o Inventário Beck de Ansiedade (BAI), instrumento que avalia os sintomas de ansiedade. Foi observada correlação positiva, moderada e estaticamente significativa entre as medidas de ansiedade e depressão, além de múltiplas formas de violência simultânea. A violência doméstica está associada a uma percepção negativa da saúde física e mental da mulher, requerendo políticas de atuação integrada que possam possibilitar maneiras eficientes de manejar este problema social.
\end{abstract}

Palavras-chave: Violência doméstica. Depressão. Ansiedade.

\begin{abstract}
The objective of this quantitative research was to evaluate the level of depression and anxiety in women victims of domestic violence, as well as characterize the type of violence. We evaluated 15 women aged between 25 and 62 years old who were admitted in a police station with a complaint of domestic violence and were psychosocial in Núcleo de Atendimento à Família e dos Autores de Violência Doméstica (NAFAVD, Center for Assistance to Family and Domestic Violence Author) of Secretaria de Estado da Mulher (SEM, Ministry of Women). Three questionnaires were applied: the first is to obtain data on the violence profile and demographics of the participants; the second is the Beck Depression Inventory (BDI), an instrument that assesses depressive symptoms; and the third, the Beck Anxiety Inventory (BAI), an instrument that assesses symptoms of anxiety. We observed a positive, moderated and statistically significant measures of anxiety and depression, besides several and simultaneous types of violence. Domestic violence is associated with a
\end{abstract}


negative perception of physical and mental health of the woman, which demands integrated policies that may promote efficient manners to deal with this social problem.

Keywords: Domestic violence. Depression. Anxiety.

\section{Introducão}

Em praticamente todo o mundo, agredir, matar, estuprar uma mulher ou uma menina são fatos considerados cada vez mais um problema social e de saúde pública. Diante disso, há mais de trinta anos Organizações começaram a se mobilizar contra esse tipo de violência, procurando compreender as motivações, estereótipos de gênero, o ciclo da violência, e as questões sociais às quais tal comportamento está ligado (Blay, 2003).

Os recentes estudos sobre comportamento violento demonstram que muitos atos dessa natureza ocorrem no ambiente doméstico. 0 lar, antes percebido como local de proteção, adquire uma perspectiva ameaçadora e sombria, que também pode propiciar a ocorrência de condutas violentas. Portanto, a hipótese de que o ambiente familiar, pelas ligações afetivas, protegeria seus membros mais vulneráveis tem se mostrado bastante falha (Day et al., 2003).

Alguns fatores estão diretamente ligados ao desenvolvimento desse comportamento violento: a persistente cultura de subordinação da mulher ao homem, uma idealização do amor romântico estimulado fortemente pelos veículos de mídia e a pouca importância que as instituições do Estado dão à denúncia e ao julgamento dos crimes contra as mulheres (Blay, 2003). Destacam-se como fator para manter esse imaginário de dominação dos homens sobre as mulheres as questões ligadas aos estereótipos de gênero: homens e mulheres possuem determinadas funções ou espaços, delimitando, assim, papéis sociais em que cada um deve ter comportamentos e posicionamentos diferenciados na sociedade (Blay, 2003).

A construção social de gênero determina as relações hierarquizadas, mediante a delimitação de papéis sociais masculinos e femininos, ensinados desde a infância, fazendo com que meninos e meninas aprendam a lidar com a emoção de maneira diferente. Enquanto as meninas são incentivadas a expressar suas emoções, mostrando delicadeza e fragilidade, os meninos são ensinados a reprimir as manifestações de algumas formas de emoção, como amor, afeto e amizade, e estimulados a exprimir outras, como raiva, agressividade e ciúmes, o que pode representar para o homem uma licença para atos violentos (Diniz, 2003).

Outro fator desencadeador da violência doméstica é o uso abusivo de substâncias psicoativas e da ingestão de bebida alcoólica na maioria das sociedades e culturas, presente nos diferentes grupos econômicos. Essas substâncias desempenham um papel desencadeante de atos violentos pela ação desinibidora da censura, assumindo o agressor condutas antes socialmente reprováveis (Day et al., 2003).

Para conter o crescimento da violência doméstica foi sancionada a Lei 11.340/2006, conhecida como Lei Maria da Penha, com o objetivo de criar mecanismos para coibir a violência doméstica e familiar contra a mulher (Brasil, 2006). Há diversas formas de violência doméstica, que podem ser classificadas como: (1) violência física - qualquer conduta que ofenda a integridade ou a saúde corporal de outro; (2) violência psicológica - qualquer conduta que cause dano emocional, à identidade ou ao desenvolvimento da pessoa; (3) violência sexual - toda ação na qual uma pessoa, em situação de poder, obriga outra à realização de práticas sexuais, utilizando força física, influência psicológica ou uso de armas ou drogas; (4) violência patrimonial - qualquer conduta que configure retenção, subtração, destruição parcial ou total de bens, documentos pessoais e instrumentos de trabalho; (5) violência moral - qualquer conduta que configure calúnia, difamação ou injúria (Brasil, 2006).

Podemos, então, classificar esses diversos tipos de violência caracterizando cada um e integrando-o num ciclo pelo qual normalmente ocorrem. Nesse ciclo, a violência física sempre é precedida pela violência psicológica, ou seja, atitudes e verbalizações que objetivam controlar, reter, tirar o dinheiro da vítima, intimidar, desqualificar sua imagem, humilhar, criticar continuamente, desvalorizar e ironizar publicamente, além de coagir, cercear, controlar os movimentos e perseguir; usar os filhos para fazer chantagens, isolar a vítima de sua rede social e fazer eameaças. Todas essas formas são utilizadas 
pelos homens na tentativa de dominar e subjugar as mulheres (Day et al., 2003). Depois dessa fase de violência psicológica, provavelmente surgirá a violência física (Hirigoyen, 2006).

Segundo Hirigoyen (2006) e Silva, Coelho e Caponi (2007), a violência física está associada a todos os outros tipos de violência, pois fere e interfere na saúde mental da mulher, na sua integridade física, moral e social. De acordo com Hirigoyen (2006), o ciclo de violência se desenvolve em três fases e de maneira repetitiva, a saber: (1) construção de tensão no relacionamento, com abusos verbais, constrangimento público, atribuição de culpa à mulher pelo fracasso, numa fase em que a vítima alimenta a expectativa de que irá reverter a situação; (2) explosão da violência - descontrole e destruição, com a violência física propriamente dita e frequentemente uso de armas brancas ou de fogo, sendo comum que todas as promessas do agressor sejam esquecidas; (3) lua de mel - arrependimento do(a) agressor(a), quando, terminando o período da violência física, o agressor demonstra remorso e medo de perder a companheira. Tal ciclo se repete, acelerando com o tempo e assumindo intensidade crescente.

Segundo Hirigoyen (2006), ao decorrer da repetição desses ciclos a tolerância da mulher aumenta, gerando nela uma sensação de normalidade da violência. Esse processo de naturalização da violência está diretamente relacionado com a cultura patriarcal em que se organiza nossa sociedade. Para que o ciclo de violência seja recorrente existem diversos fatores: dependência financeira e afetiva, inversão da culpa, presente tanto pela declaração explícita de seus companheiros (como se eles as agredissem por culpa delas), quanto pela crença de não ter feito seu papel como mulher corretamente, já que, no imaginário social, está atrelada à mulher a responsabilidade do bom andamento da relação conjugal.

Algumas mulheres, porém, com apoio de entidades de suporte jurídico-legal, "juntaram forças" para romper esse ciclo. Em muitos casos, a mulher somente consegue se desvencilhar do agressor com o suporte dos órgãos destinados a esses casos. 0 fato de as mulheres não romperem com o ciclo demonstra cada vez mais a necessidade de ajuda de agentes externos (Hirigoyen, 2006).

Trabalhar sobre as bases dessa culpa seria uma forma de provocar mudanças significativas na construção de autonomia da mulher, para assim conseguir romper com a relação de violência. Diniz (2003) argumenta que a sociedade deve encontrar meios de dar voz e poder às mulheres, a partir principalmente de mudanças nos padrões culturais patriarcais, conscientização sobre atitudes violentas e promoção do atendimento eficiente às vítimas.

De acordo com Narvaz e Koller (2006), nessa situação de violência doméstica, é necessário compreender os papéis estereotipados de gênero que são veiculados pela cultura e que tornam invisíveis a produção e reprodução da subordinação feminina, que é um aspecto que favorece a ocorrência de abusos. Esses papéis são construídos ao longo dos anos, e qualquer mudança perpassa por uma abordagem focalizada nesse aspecto. Os processos relacionados com o gênero influenciam o comportamento, os pensamentos, os sentimentos dos indivíduos e afetam as interações sociais (Saavedra \& Nogueira, 2006).

Conforme Narvaz e Koller (2006), é necessário investir no apoio e na compreensão da vivência das vítimas para favorecer a informação, valorizar e incentivar a iniciativa a resistências e denúncia dos abusos sofridos. Portanto, é preciso promover aprofundadas reflexões éticas, epistemológicas e metodológicas relativas às formas como as investigações são conduzidas, com o intuito de avaliar o impacto que pode ser causado pela intervenção de pesquisa. É preciso haver uma articulação da academia, da pesquisa, da clínica e da política como possibilidade de empoderamento de grupos historicamente oprimidos (Neves \& Nogueira, 2003 citados por Narvaz \& Koller, 2006).

A Lei Maria da Penha busca garantir proteção e procedimentos policiais e judiciais humanizados para as vítimas, punição e reeducação para os agressores. Aspectos conceituais e educativos são inseridos para a promoção de mudanças nos valores sociais que naturalizam a violência no âmbito doméstico, apresentando-se como uma legislação moderna, avançada e inovadora (Brasil, 2006). Entretanto, segundo dados da Fundação Perseu Abramo (Venturi, Recamán, \& Oliveira, 2010), duas em cada três pessoas atendidas nos hospitais em razão de violência doméstica são mulheres; em $51,6 \%$ dos atendimentos foi registrada reincidência no exercício da violência contra a mulher. Em 66\% dos casos, os responsáveis pelas agressões foram os maridos ou companheiros e $66 \%$ das brasileiras acham que a violência doméstica e familiar contra as mulheres aumentou, mas $60 \%$ acreditam que a proteção contra esse

Psicol. Argum. 2013 jul./set., 31 (74), 447-456 
tipo de agressão melhorou após a criação da Lei Maria da Penha. Além disso, a pesquisa indica que seis em cada dez brasileiros conhecem alguma mulher que foi vítima de violência doméstica e desse total, 63\% tomaram alguma atitude para ajudar a vítima.

Esse mesmo estudo indicou razões para uma mulher continuar em uma relação violenta: para 27\%, a falta de condições econômicas para se sustentar; para $20 \%$, a falta de condições para criar os filhos; e para $15 \%$, o medo de ser morta. Dessas mulheres entrevistadas, $27 \%$ declararam já ter sido vítimas de violência doméstica e das que relataram terem sido agredidas, $15 \%$ disseram terem sido obrigadas a fazer sexo com os companheiros. Os dados revelam que 94\% sabem da existência da Lei Maria da Penha, mas apenas 13\% sabem seu conteúdo.

O Brasil assumiu um compromisso de combater qualquer discriminação, comprometendo-se a tentar mudar a cultura patriarcal que aterroriza muitas mulheres. 0 país é signatário da Convenção sobre a Eliminação de Todas as Formas de Discriminação contra Mulher, adotada pela Resolução n. 24/180 da Assembleia Geral da ONU, em 18 de dezembro de 1979; no entanto, foi apenas em 1ํo de fevereiro de 1984 que o Brasil assinou a Convenção, decretando sua promulgação em 13 de setembro de 2002, com o decreto n. 4.377 (Secretaria Especial de Direitos Humanos, 2006).

Um dos maiores avanços da Lei Maria da Penha é a previsão de medidas protetivas, tanto para impor obrigações ao agressor, quanto para resguardar a mulher e sua família. No primeiro caso, pode determinar a proibição ou suspensão do porte de arma do agressor; o afastamento do lar ou de local de convivência com a mulher; impedir que se aproxime e se comunique com a ofendida e seus familiares; proibir que frequente determinados locais; restringir ou suspender as visitas aos filhos e obrigar a prestação de alimentos (Brasil, 2006).

Quanto à proteção da mulher e seus dependentes, o juiz pode: determinar o encaminhamento para programa de proteção e atendimento e a recondução para o lar, após o afastamento do agressor; autorizar o seu afastamento sem perder o direito aos bens, guarda dos filhos; decidir sobre a separação de corpos e proteção do seu patrimônio, restituindo bens indevidamente subtraídos pelo agressor; proibir a celebração de atos e contratos, suspender procurações, prestação de caução provisória.
Essas medidas protetivas podem ser cumulativas. A qualquer momento elas podem ser substituídas e revistas; podem também ser acrescentadas novas ações, concedidas a pedido do Ministério Público ou da ofendida e ser instauradas de imediato, independentemente de audiência (Brasil, 2006). A Lei 11.340/06 enfatiza a criação de equipe multidisciplinar formada por profissionais da área psicossocial, jurídica e da saúde, que deve desenvolver trabalhos de orientação, encaminhamento, prevenção e atendimento das partes envolvidas na violência. A lei também estabelece para o Estado a adoção de políticas públicas de prevenção, assistência e repressão à violência contra as mulheres. Por todas essas características e inovações, é uma lei integral, que prioriza o caráter educativo, tendo como objetivo a promoção de mudança nos valores sociais (Brasil, 2006).

Os efeitos da violência conjugal são inúmeros para todos os envolvidos, causando vários danos e sequelas, imediatos ou tardios. Eles têm possibilidade de fragilizar as vítimas e ter implicações permanentes na saúde física e mental, podendo comprometer e reduzir as possibilidades de defesa e deixar as vítimas menos seguras de seus valores e de seus limites pessoais (Adeodato, Carvalho, Siqueira \& Souza, 2005).

A mulher passa a não registrar mais a violência, a trivializá-la e pode até rir ao relatar os seus dramas, o que causa raiva, desqualificação e antipatia da parte de quem a escuta. Ela convalida o discurso do agressor, ou seja, apenas repete o seu discurso sem pensar a partir de si mesma. Crê que necessita dele para sobreviver; protege, justifica e se identifica com ele. A mulher pode parecer agressiva com terceiros ao apresentar os riscos que o parceiro oferece, pois pensa que seus problemas acabariam se fosse capaz de entendê-lo (Ravazzola, 1997). Os estudos da violência doméstica exigem uma atitude de muita tolerância e sensibilidade, pois as emoções envolvidas despertam tristeza, raiva e impotência.

Os atendimentos na rede de saúde pública de todo o Brasil revelam um quadro de profunda gravidade na saúde das mulheres em situação de violência (Schraiber, 2005). Independentemente da espécie de violência sofrida, as mulheres apresentam vários sintomas físicos, como: cefaleias, dores, palpitações, tontura, mal-estar, hematomas, fraturas, distúrbios gastrointestinais, dores musculares e inespecíficas em várias partes do corpo, perda ou aumento de peso, contusões, escoriações, quadros 
inflamatórios, incômodos difíceis de serem localizados e diagnosticados, dor pélvica, infecções urinárias, gravidez indesejada, aborto espontâneo, transtornos psicossomáticos, distúrbios mentais ou comportamentos obsessivo-compulsivos (Day et al., 2003).

Os sintomas psicológicos quase sempre são: depressão, síndrome de estresse pós-traumático, ansiedade, fobias, desânimo, irritabilidade, síndrome do pânico, sensação de perigo iminente, ideação suicida, tentativa de suicídio, homicídio, baixa autoestima, sentimentos de culpa, inferioridade, insegurança, vergonha, isolamento social, dificuldade de tomada de decisão, dependência ao extremo, hábito de fumar, uso de álcool, falta de concentração (Day et al., 2003). De acordo com Grossi (1995), mulheres que sofrem violência doméstica estão cinco vezes mais predispostas a apresentarem problemas psicológicos em comparação às mulheres que não vivenciam essa situação. Muitas vezes, a violência psicológica causa sequelas ainda mais graves que efeitos físicos. Surgem também sintomas sociais, apresentando faltas no trabalho, ausência ao serviço de saúde, isolamento, mudanças frequentes de emprego ou de cidade (Schraiber, 2005; Silva et al., 2007).

De acordo com o Manual Diagnóstico e Estatístico de Transtornos Mentais (DSM-IV) (American Psychiatric Association [APA], 2002), a ansiedade se refere ao fenômeno que, dependendo de sua circunstancialidade ou intensidade, pode ser útil ou tornar-se patológico, prejudicando o funcionamento psíquico e somático. Em níveis normais, trata-se de fenômeno fisiológico responsável pela adaptação do organismo em situações de perigo. Entretanto, quando a ansiedade é excedente, em vez de contribuir para a adaptação, desencadeia a falência da capacidade adaptativa. Cognitivamente, a ansiedade se manifesta por meio da consciência das sensações fisiológicas de sudorese, palpitação, inquietação e outros sintomas do sistema nervoso autônomo. Os critérios diagnósticos para o transtorno de ansiedade são: inquietação ou sensação de estar com os nervos à flor da pele; fadiga; dificuldade em concentrar-se; irritabilidade; tensão muscular, tamborilar dos dedos dos pés ou das mãos e perturbação no sono. Diante de uma situação estressora, o tipo e o grau da resposta de cada pessoa não dependerá apenas da força, importância e frequência do evento de vida estressor. Dependerá sim da capacidade de cada um em interpretar, avaliar e enfrentar as vivências estressoras.
Quanto à depressão, alguns comportamentos peculiares permitem que o diagnóstico seja realizado de maneira precisa segundo critérios do DSM-IV (APA, 2002). Os critérios diagnósticos para o episódio depressivo são: a falta de interesse em realizar atividades que antes eram consideradas como prazerosas pelo indivíduo; humor deprimido diariamente com sentimento de tristeza; perda ou ganho significativo de peso, sem realizar qualquer regime ou dieta; insônia ou hipersonia quase todos os dias; sensação de fadiga, mesmo não tendo realizado qualquer atividade física; sentimentos de culpa e inutilidade; pensamentos de ruína, destruição ou suicídio (ou tentativa).

É possível também encontrar informações acerca da depressão, de forma bem delimitada, para a elaboração de um diagnóstico na Classificação Internacional de Doenças (CID-10, 1993). No referido manual encontramos que o humor do depressivo varia pouco de dia para dia, ou segundo as circunstâncias e pode se acompanhar de sintomas ditos "somáticos", como perda de interesse ou prazer, despertar matinal precoce, agravamento matinal da depressão, lentidão psicomotora importante, agitação, perda de apetite, perda de peso e perda da libido. 0 número e a gravidade dos sintomas permitem determinar quatro graus de um episódio depressivo: mínima, leve, moderado e grave.

A depressão é uma das principais consequências da violência conjugal para as mulheres, pois observa-se que as parceiras que continuam no relacionamento violento estão mais predispostas a desencadear a depressão. Jacobucci e Cabral (2004) destacam sintomas associados à vivência doméstica, tais como sentimentos de solidão, tristeza, desamparo, descrença, irritação, baixa autoestima e baixa autoconfiança.

A maioria dos estudos sobre as consequências da violência conjugal dizem respeito à saúde da mulher, justamente pelo fato de ser a principal vítima a sofrer implicações. Estima-se que a violência de gênero seja responsável por mais óbitos de mulheres entre 15 e 44 anos do que câncer, malária, HIV, problemas respiratórios, metabólicos, infecciosos, acidentes de trânsito e guerras (Adeodato et al., 2005).

Experiências de violência doméstica deixam marcas na saúde física e mental e afetam tanto a vida pública quanto a vida privada, gerando um processo de autodesvalorização. No entanto, ainda são necessários estudos que investiguem níveis de depressão e ansiedade em mulheres que sofreram violência, bem

Psicol. Argum. 2013 jul./set., 31 (74), 447-456 
como caracterizem o contexto de violência doméstica. Portanto, o objetivo dessa pesquisa quantitativa foi avaliar o nível de ansiedade e depressão em mulheres vítimas da violência doméstica, além de caracterizar os tipos de violência sofrida, tipo de vínculo com o agressor e dados sociodemográficos das vítimas.

\section{Método}

\section{Participantes}

Foram avaliadas 15 mulheres vítimas de violência doméstica com idades entre 25 a 62 anos, com média $39,1 \pm 10,4$ anos. 0 tempo de relacionamento com o agressor variou entre 6 meses e 26 anos (média =12,8 \pm 7,7 anos). Entre as participantes, oito são casadas, cinco estão em união estável e duas namoram; as crenças religiosas relatadas foram a evangélica e a católica e os níveis de escolaridade incluem desde analfabetismo até superior incompleto.

Foram obedecidos os seguintes critérios de inclusão: ter registrado ocorrência policial sobre a violência doméstica, participar do atendimento psicossocial no Núcleo de Atendimento a Família e dos Autores de Violência Doméstica (NAFAVD) da Secretaria de Estado da Mulher (SEM).

\section{Instrumentos}

Foram utilizados três instrumentos para coleta de dados aplicados na forma de entrevista:

1) Questionário sociodemográfico, para obter dados pessoais e sobre o perfil da violência: vínculo com o autor do fato, histórico da agressão e intervenção dos serviços sociais e também dados demográficos das participantes.

2) Inventário Beck de Depressão (BDI), instrumento que avalia os sintomas depressivos, em que o escore total é a soma da pontuação de 21 itens ( 0 a 63), com os seguintes pontos de corte: até 4 pontos sem depressão ou depressão mínima, 5-7 pontos para depressão média, 8-15 pontos para depressão moderada e 16 pontos ou mais para depressão grave (Cunha, 2001).

3) Inventário Beck de Ansiedade (BAI), instrumento que mede a intensidade dos sintomas de ansiedade, em que o escore total é a soma das pontuações de 21 itens ( 0 a 63), com os seguintes pontos de corte: 0-7 pontos para nível mínimo de ansiedade, 8-15 pontos para nível leve, $16-25$ pontos para nível moderado e 26-63 pontos para nível grave (Cunha, 2001).

\section{Procedimento}

Inicialmente, o projeto foi submetido ao Comitê de Ética em pesquisa da Universidade Católica de Brasília, tendo sido aprovado em 24 de setembro de 2012 sob protocolo n. 108.238. Posteriormente, a pesquisadora convidou 20 mulheres do atendimento psicossocial no NAFAVD para participar do estudo, porém cinco recusaram, alegando indisponibilidade de tempo. Após assinatura do Termo de Consentimento Livre e Esclarecido, foi explicado detalhadamente o procedimento e indicados o tempo da realização das entrevistas (com duração de aproximadamente 30 minutos) e as datas marcadas para as sessões. Por fim, foram aplicados os três questionários individualmente e em ambiente sigiloso.

\section{Resultados}

A Tabela 1 apresenta dados sociodemográficos da amostra vítima de violência doméstica e dados sobre o tipo de agressão infligida.

Destacam-se os principais dados apresentados na Tabela 1.0 vínculo com os agressores incluiu modalidades diversas, com relatos de mulheres casadas, com união estável e com namorados/noivos. Seis participantes vivem junto com os seus companheiros e nove referiram que não estão vivendo junto com os seus companheiros, enfatizando que a violência pode acontecer no namoro, casamento e permanecer muitas vezes após a separação. A quantidade de filhos chegou a cinco; apenas três mulheres relataram que não são mães. Todas as participantes declararam renda familiar inferior a cinco salários mínimos.

Nove participantes citaram que seus companheiros fazem uso de bebida alcoólica, um consome drogas ilícitas e cinco não ingerem bebida alcoólica nem fazem uso de entorpecentes. 0 requerimento das medidas protetivas de urgência, previstas na Lei Maria da Penha, foram concedidas a 12 
Tabela 1 - Dados demográficos da mulher agredida e dados da violência doméstica

\begin{tabular}{lcc}
\hline Variáveis & Sim & Não \\
\hline Natural do Distrito Federal & 7 & 8 \\
Religião & 13 & 2 \\
Filhos & 12 & 3 \\
Casados & 8 & - \\
Namorados/Noivos & 2 & - \\
Companheiros/União estável & 5 & - \\
Vivendo juntos & 6 & 9 \\
Sofreu agressão anterior & 5 & 10 \\
Requerimento de medidas protetivas & 12 & 3 \\
Sentiu-se protegida com a intervenção da & 12 & 3 \\
justiça & & \\
Conhece a Lei Maria da Penha & 14 & 1 \\
Acredita que a lei Maria da Penha influen- & 13 & 2 \\
ciou na redução da violência doméstica & & \\
contra a mulher & & \\
\hline
\end{tabular}

Fonte: Dados da pesquisa.

participantes que fizeram o requerimento, fato que gerou relatos de se sentirem mais protegidas com a intervenção da justiça; 13 mulheres acreditam que a Lei Maria da Penha influenciou na redução da violência doméstica contra a mulher. A Tabela 2 apresenta outros dados sobre a violência doméstica segundo relatos das 15 participantes.

Ressaltam-se distintos tipos de comportamentos dos agressores, incluindo relatos de ciúmes, possessividade e agressividade; sete participantes citaram mais de um comportamento típico por parte de seus companheiros. Os dados revelam que a maioria das participantes já sofreu mais de uma agressão e apenas duas participantes relataram não ter sofrido violência psicológica, resultados que enfatizam tipos de agressão concomitantes, dado comum no episódio de violência doméstica. As agressões sexuais e patrimoniais foram os tipos menos frequentes. Treze participantes sofreram agressões dentro de casa e seis mulheres sofreram agressões em via pública.

A Tabela 3 apresenta as pontuações obtidas no Inventário Beck de Depressão e Inventário Beck de Ansiedade.

A média nos escores do BDI correspondeu a $28,8 \pm 8,5$ pontos. Ressalta-se que 13 participantes estão em um grau de depressão grave e duas em nível de depressão moderada. A partir de itens
Tabela 2 - Outros dados sobre a violência doméstica sofrida

\begin{tabular}{lc}
\hline Dados sobre a violência sofrida & Frequência \\
\hline Comportamento do agressor & 9 \\
Ciumento & 7 \\
Possessivo & 6 \\
Agressivo & 2 \\
Sem resposta & \\
\hline Tipos de agressão sofrida & 13 \\
Lesão corporal & 13 \\
Ameaças & 13 \\
Violência psicológica & 2 \\
Violência sexual & 2 \\
Violência patrimonial & \\
\hline Local em que ocorreu a agressão & 13 \\
Dentro de casa & 6 \\
Via pública & 3 \\
Local de trabalho & 2 \\
\hline Outros locais & \\
\hline
\end{tabular}

Fonte: Dados da pesquisa.

Tabela 3 - Pontuações em depressão e ansiedade segundo Inventários Beck

\begin{tabular}{lc}
\hline Níveis de depressão & Frequência \\
\hline Sem depressão ou depressão mínima & 0 \\
Depressão média & 0 \\
Depressão moderada & 2 \\
Depressão grave & 13 \\
\hline Níveis de ansiedade & Frequência \\
\hline Ansiedade mínima & 0 \\
Ansiedade leve & 2 \\
Ansiedade moderada & 2 \\
Ansiedade severa & 11 \\
\hline
\end{tabular}

Fonte: Dados da pesquisa.

específicos do BDI, foi possível constatar que cinco mulheres pensaram na possibilidade de suicídio, participantes estas que sofreram mais de um tipo de agressão, incluindo violência física, psicológica e sexual.

Considerando os níveis de ansiedade, destaca-se que 11 participantes estão em um nível severo de ansiedade, duas mulheres em um nível moderado e duas participantes em nível leve. A Tabela 4 apresenta análises inferenciais sobre associações entre

Psicol. Argum. 2013 jul./set., 31 (74), 447-456 
Tabela 4 - Associações entre ansiedade, depressão, idade, tempo de relacionamento e número de filhos

\begin{tabular}{lcccc}
\hline Variáveis & $\mathbf{1}$ & $\mathbf{2}$ & $\mathbf{3}$ & $\mathbf{4}$ \\
\hline 1. Ansiedade & - & & & \\
2. Depressão & $0,69^{* *}$ & - & & \\
3. Idade & $-0,18$ & 0,17 & - & \\
$\begin{array}{l}\text { 4. Tempo de relaciona- } \\
\quad\end{array} \quad-0,07$ & 0,03 & $0,57^{*}$ & - \\
$\quad$ mento & & & & \\
5. Filhos & 0,38 & 0,35 & $0,84^{*}$ & 0,58 \\
\hline
\end{tabular}

Legenda: ${ }^{*} \mathrm{p}<0.05 ;{ }^{* *} \mathrm{p}=0.004$.

Fonte: Dados da pesquisa.

ansiedade, depressão, idade, tempo de relacionamento e número de filhos.

Destaca-se especialmente a correlação positiva, moderada e estatisticamente significativa entre as medidas de ansiedade e depressão. Outras associações entre idade e tempo de relacionamento com o autor da violência ou número de filhos também foram estatisticamente significativas, porém não houve correlação relevante entre medidas de ansiedade e depressão e as demais variáveis.

Foram analisadas associações inferenciais entre medidas de ansiedade e depressão e os seguintes dados da amostra: procedência, escolaridade, presença de filhos, local do fato, vínculo com o autor da agressão, presença de ocorrências violentas anteriores e tipo de violência impetrada; porém não houve associações estatisticamente significativas entre os resultados.

\section{Discussão}

Esta pesquisa apresenta dados que podem contribuir para a preparação mais eficiente para o atendimento de vítimas de violência doméstica e corrobora alguns dados da literatura. Neste estudo, 13 das participantes relataram ter sofrido agressões dentro de casa, o que também ocorreu no estudo de Adeodato et al. (2005), em que a maioria dos caso de violência contra mulheres ocorria em casa, sendo que os agressores eram, na maioria das vezes, parceiros íntimos e com alta possibilidade de novas agressões, aspecto que pode enfatizar a grande dificuldade em mudar a situação de violência.

As vítimas podem entender que sofrem a violência doméstica, porém não rompem com essa situação devido a inúmeras questões; algumas resistem, outras fogem e outras tentam manter a paz, submetendo-se às exigências de seus companheiros. Os motivos mais alegados para continuar um relacionamento abusivo são: perda do suporte da família e dos amigos, a esperança de que "ele vai mudar um dia", medo da represália, perda do suporte financeiro, preocupação com os filhos e dependência emocional e financeira (Day et al., 2003).

Apesar das dificuldades, muitas mulheres acabam abandonando os parceiros violentos. Elas entram em um processo de quebra de sua negação, racionalização, culpa e submissão, passando, então, a se identificar com outras pessoas na mesma situação (Day et al., 2003). A violência doméstica ocorre numa relação afetiva, cuja ruptura pode depender de intervenção externa. Até que isso aconteça, a escalada descreve uma trajetória oscilante, com movimentos de saída da relação e de retorno (Hirigoyen, 2006). Os resultados deste estudo enfatizam a necessidade de aprofundar as ações preventivas à violência doméstica e de investir na conscientização e na qualidade da assistência às vítimas, bem como na disseminação do conhecimento sobre a legislação brasileira relativa à violência doméstica. Esses elementos são relevantes em razão da qualificação do tipo de violência sofrida, dos locais da agressão, do tipo de vínculo com o autor do fato.

As mulheres são as que correm maiores riscos de sofrer violência em ambientes domésticos e familiares e, segundo as estimativas da Organização Mundial de Saúde (Krug, Dahlberg, Mercy, Zwi \& Lozano, 2002), uma em cada quatro mulheres é vítima de abusos sexuais cometidos por seu parceiro ao longo da vida. Violência entre casais inclui atos de agressão física, assédio psicológico, atos forçados e diversos tipos de comportamentos, como isolar uma pessoa de sua família e amigos ou restringir seu acesso à informação ou ajuda. Os resultados deste estudo corroboram esses dados ao mostrar tipos diferentes de agressão ocorrendo simultaneamente. Segundo Herigoyen (2006), a violência doméstica começa sutilmente, até chegar a ápices quase impossíveis de suportar e com tipos variados de agressão ocorrendo em conjunto.

Schraiber (2005) e Silva et al. (2007) destacam a grande incidência e a gravidade da violência psicológica. Embora não haja a ocorrência de marcas físicas, esse tipo de agressão acarreta profundos danos à autoestima da mulher e à sua 
saúde geral. Entre os quadros orgânicos resultantes, encontram-se obesidade, síndrome de dor crônica, distúrbios gastrintestinais, fumo, distúrbios ginecológicos e outros (Day et al., 2003). No presente estudo, quase todas as mulheres informaram ter sofrido ameaças ou agressão de ordem psicológica, destacando a necessidade de compreender de forma aprofundada a vivência dessas vítimas e também de seus agressores.

Muitas vezes, as sequelas psicológicas do abuso são ainda mais graves que seus efeitos físicos, pois tal experiência destrói a autoestima da mulher, expondo-a a um risco mais elevado a apresentar problemas mentais como depressão, fobia, estresse pós-traumático, tendências ao suicídio e consumo abusivo de álcool e drogas (Schraiber, 2005; Silva et al., 2007). Outro aspecto relevante encontrado nesta pesquisa foi o fato de que cinco mulheres pensaram na possibilidade de suicídio, dado que enfatiza a necessidade de detecção precoce de manifestações de ansiedade e depressão, para possibilitar estratégias preventivas à ideação suicida.

A falta de um diagnóstico preciso traz sérias consequências não só às mulheres agredidas, mas também para o sistema de saúde. Nesse contexto, ressalta-se o uso de instrumentos validados como uma possibilidade relevante de compreender efeitos psicológicos relativos a sintomas de depressão e ansiedade, associados à violência. Foram verificados neste estudo escores compatíveis com níveis importantes de depressão e ansiedade, tendo em vista que 13 mulheres atingiram níveis elevados de depressão e 11 apresentaram altos níveis de ansiedade.

Destaca-se ainda correlação positiva, moderada e estatisticamente significativa entre as manifestações de depressão e ansiedade, indicada na análise inferencial. A análise específica de itens contidos no BDI e BAI ressalta que as participantes exprimem sentimentos de solidão, tristeza crônica, desamparo, irritação, descrenças, culpa, desânimo, indecisão, autocrítica, falta de concentração, passividade, deficit em habilidade sociais, insônia, perda de apetite e do interesse sexual. Esses dados confirmam estudos de Schraiber (2005), enfatizando que a violência conjugal a que a mulher se submete compromete a saúde física e mental. As vítimas da violência doméstica que desenvolvem depressão passam a ter sentimentos inapropriados de desesperança, desprezando-se como pessoa e até mesmo se culpando pelo contexto de violência doméstica (Schraiber, 2005).

\section{Considerações finais}

A violência doméstica é entendida como todo tipo de violência praticada no âmbito privado por pessoas que convivam ou se relacionem afetivamente com a vítima. É um tema atual, que vem sendo amplamente debatido e investigado nas mais diferentes áreas do conhecimento. Trata-se de um fenômeno de alta prevalência, considerado como um problema de saúde pública e de violação de direitos humanos.

A questão de saúde pública poderia ser tratada de maneira adequada se a estrutura dos centros de atendimento estivesse preparada para atender às vítimas, tendo em vista as relevantes mudanças de comportamento nessas mulheres como depressão em decorrência aos maus tratos e opressão em suas próprias casas.

A violência não pode ser vista como um fenômeno inerente à natureza humana, mas como um fenômeno condicionado ao modo de organização social, que é historicamente construído, pois existe uma relação de opressor e oprimido, onde este somente deixará de ser oprimido a partir do momento em que começa a desenvolver uma luta por liberdade e exigência de seus direitos (Day et al., 2003).

Percebe-se, portanto, a necessidade de que esse ciclo da violência seja estudado e pesquisado de modo aprofundado. Neste sentido, é imprescindível que os profissionais que atendem denúncias estejam preparados para: (a) direcionar um olhar atento que possibilite à pessoa se identificar como vítima ou ter condições de perceber a violência ainda em estágio inicial; (b) atuar sob a perspectiva dos Direitos Humanos e crimes contra a pessoa, entendendo a violência como um fenômeno sistêmico e socio-histórico; (c) possibilitar acolhimento à vítima e às demais pessoas de suas relações, favorecendo a busca de soluções por meio de mecanismos legais e do exercício da cidadania; e (d) prestar um atendimento respeitoso, de modo a contribuir para que a vítima possa se expressar livremente.

\section{Referências}

Adeodato,V. G., Carvalho, R. R., Siqueira, V. R., \& Souza, F. G. M. (2005). Qualidade de vida e depressão em mulheres vítimas de seus parceiros. Revista de Saúde Pública, 39(1), 108-113.

Psicol. Argum. 2013 jul./set., 31 (74), 447-456 
Blay, E. A. (2003). Violência contra a mulher e políticas públicas. Estudos Avançados, 17(49), 87-98.

Brasil (2006). Lei n. 11.340 de 7 de agosto de 2006. Cria mecanismos para coibir a violência doméstica e familiar contra a mulher, nos termos do $\S 8^{\circ}$ do art. 226 da Constituição Federal, da Convenção sobre a Eliminação de Todas as Formas de Discriminação contraas Mulheres e da Convenção Interamericana para Prevenir, Punir e Erradicar a Violência contra a Mulher; dispõe sobre a criação dos Juizados de Violência Doméstica e Familiar contra a Mulher; altera o Código de Processo Penal, o Código Penal ea Lei de Execução Penal; e dá outras providências. Brasília. Recuperado em 9 set. 2013, de http:// www.planalto.gov.br/ccivil_03/_ato2004-2006/ 2006/lei/l11340.htm

CID-10 (1993). Classificação de transtornos mentais e de comportamento da CID-10: Descrições clínicas e diretrizes diagnósticas. Porto Alegre: Artmed.

American Psychiatric Association [APA] (2002). Manual diagnóstico e estatístico de transtornos mentais - DSM - IV - TR. Porto Alegre: Artmed.

Cunha, J. A. (2001). Manual da versão em português das escalas Beck. São Paulo: Casa do Psicólogo.

Day, V. P., Telles, L. E. B., Zoratto, P. H., Azambuja, M. R. F., Machado, D. A., Silveira, M. B., Debiaggi, M., Reis, M. G., Cardoso, R. G., \& Blank, P. (2003). Violência doméstica e suas diferentes manifestações. Revista de psiquiatria do Rio Grande do Sul, 25(1), 9-21.

Diniz, F. P. A. (2003). Violência doméstica: Por que é tão difícil lidar com ela? Revista de Psicologia da Unesp, 2(1), 20-35.

Grossi, P. K. (1995). Violência contra mulher: Mitos e fatos. Educação, 18(29),93-99.
Hirigoyen, M. F. (2006). A Violência no casal: Da coação psicológica à agressão física. Rio de Janeiro: Bertrand Brasil.

Jacobucci, P. G., \& Cabral, M. A. A. (2004). Depressão e traços de personalidade em mulheres vítimas de violência doméstica. Revista Brasileira de Psiquiatria, 26(3), 215.

Krug, E. G., Dahlberg, L. L., Mercy, J. A., Zwi, A. B., \& Lozano, R. (Coord.). (2002). Relatório mundial violência e saúde. Genebra: Organização Mundial de Saúde.

Narvaz, M. G., \& Koller, S. H. (2006). Mulheres vítimas de violência doméstica: Compreendendo subjetividades assujeitadas. Psico, 37(1), 7-13.

Ravazzola, M. C. (1997). Histórias infames: Los maltratos en las relaciones. Buenos Aires: Paidós.

Saavedra, L., \& Nogueira, C. (2006). Memórias sobre o feminismo na psicologia: Para a construção de memórias futuras. Memorandum,11, 113- 127.

Schraiber, L. B. (2005). Violência dói e não é direito: A violência contra a mulher, a saúde e os direitos humanos. São Paulo: Unesp.

Secretaria Especial de Direitos Humanos (2006). Direitos humanos e Documentos Internacionais. Brasília: Previdência da República, Secretaria Especial de Direitos Humanos.

Silva, L. L., Coelho, E. B. S., \& Caponi, S. N. C. (2007). Violência silenciosa: Violência psicológica como condições da violência física doméstica. Interface Comunicação, Saúde, Educação, 11(21), 93-103.

Venturi, G., Recamán, M., \& Oliveira, (Org.). (2010). A mulher brasileira nos espaços público e privado: Como vivem e o que pensam as mulheres no século XXI. Recuperado em 9 set. 2013, de http://library.fes.de/ pdf-files/bueros/brasilien/05629-introd.pdf 